\title{
CDISC SDTM Lung Cancer Findings About Test Name Terminology
}

National Cancer Institute

\section{Source}

National Cancer Institute. CDISC SDTM Lung Cancer Findings About Test Name

Terminology. NCl Thesaurus. Code C154688.

Terminology associated with the lung cancer findings about test name codelist of the Clinical Data Interchange Standards Consortium (CDISC) Study Data Tabulation Model (SDTM). 